\title{
A evolução das exportações de arroz brasileiro e a competitividade frente a países do
}

\section{Mercosul}

\author{
The evolution of rice Brazilian exports and its competitiveness face on Mercosur countries \\ La evolución de las exportaciones brasileñas de arroz y la competitividad contra los países del
}

Mercosur

Recebido: 23/09/2021 | Revisado: 30/09/2021 | Aceito: 06/10/2021 | Publicado: 10/10/2021

Leandro Kenji Inagaki Sato

ORCID: https://orcid.org/0000-0001-6378-7881

Universidade Federal da Grande Dourados, Brasil

E-mail: le_inagaki@hotmail.com

João Gilberto Mendes dos Reis

ORCID: https://orcid.org/0000-0001-6409-2299

Universidade Federal da Grande Dourados, Brasil Universidade Paulista, Brasil

E-mail: joao.reis@docente.unip.br

Antônio Carlos Vaz Lopes

ORCID: https://orcid.org/0000-0002-3209-3331

Universidade Federal da Grande Dourados, Brasil E-mail: antoniolopes@ufgd.edu.br

Alexandre Formigoni

ORCID: https://orcid.org/0000-0001-7487-0541

Centro Estadual de Educação Tecnológica Paula Souza, Brasil

E-mail: a_formigoni@yahoo.com.br

\begin{abstract}
Resumo
A abertura do Mercado Comum do Sul, chamado de Mercosul, trouxe profundas mudanças para a produção e comercialização dos produtos agrícolas brasileiros. No caso do arroz, por exemplo, a produção interna começou a ser substituida pela importação do cereal produzido nos países do bloco com preços mais baixos. Isso fez com que o país precisasse buscar novos mercados para poder vender o excedente de sua produção. Este cenário trouxe problemas para os produtores de arroz brasileiros já que os custo para se produzir nos outros países do Mercosul são mais baixos. Frente a este problema, o objetivo deste estudo foi de analisar como a exportação de arroz brasileira se comportou ao longo dos anos, e a competitividade em relação aos países do Mercosul. Para atingir esse objetivo foram realizados estudos estatísticos descritivos das exportações do Brasil com a criação de gráficos e tabelas utilizando o software Microsoft Excel ${ }^{\circledR}$. Posteriormente, foi feito um estudo de competitividade comparando índices do Brasil com países do Mercosul. Foram utilizados três índices: o Índice de Vantagem Comparativa Revelada (IVCR), Taxa de Cobertura (TC) e o Índice de Orientação Regional (IOR). Os resultados mostraram que o Brasil evoluiu muito nas exportações de arroz e melhorou a competividade do seu produto. Apesar disso, ainda apresenta índices menores que todos os países que foram comparados no estudo.
\end{abstract}

Palavras-chave: Agronegócio; Comércio internacional; Rizicultura; Vantagem competitiva.

\begin{abstract}
The opening of the Southern Common Market, called Mercosur, brought profound changes to the production and marketing of Brazilian agricultural products. In the case of rice, for instance, domestic production began to be replaced by imports of cereal produced in the other countries with lower prices. This made the country need to look for new markets to be able to sell the surplus of its production. This scenario brought problems for Brazilian rice producers as the cost to produce in other Mercosur countries is lower. Faced with this problem, the objective of this study was to analyze how Brazilian rice exports behaved over the years, its competitiveness in relation to Mercosur countries. To achieve this objective, descriptive statistical studies of exports from Brazil were carried out with the creation of graphs and tables using Microsoft Excel ${ }^{\circledR}$ software. Subsequently, a competitiveness study was carried out comparing indices in Brazil with Mercosur countries. Three indexes were used: the Revealed Comparative Advantage Index (IVCR), Coverage Rate (TC) and the Regional Orientation Index (IOR). The results showed that Brazil evolved a lot in rice exports and improved the competitiveness of its product. Despite this fact, it still has lower rates than all the countries that were compared in the study.
\end{abstract}

Keywords: Agribusiness; International trade; Rice production; Competitive advantage. 


\begin{abstract}
Resumen
La apertura del Mercado Común del Sur, denominado Mercosur, trajo cambios profundos en la producción y comercialización de los productos agrícolas brasileños. En el caso del arroz, por ejemplo, la producción nacional comenzó a ser reemplazada por importaciones de cereales producidos en los países del bloque con precios más bajos. Esto hizo que el país necesitara buscar nuevos mercados para poder vender el excedente de su producción. Este escenario trajo problemas para los productores de arroz brasileños ya que el costo de producción en otros países del Mercosur es menor. Ante este problema, el objetivo de este estudio fue analizar cómo se comportaron las exportaciones de arroz brasileño a lo largo de los años, su competitividad en relación con los países del Mercosur. Para lograr este objetivo, se realizaron estudios estadísticos descriptivos de las exportaciones de Brasil con la creación de gráficos y tablas utilizando el software Microsoft Excel®. Posteriormente, se realizó un estudio de competitividad comparando índices de Brasil con los de los países del Mercosur. Se utilizaron tres índices: el Índice de Ventaja Comparativa Revelada (IVCR), la Tasa de Cobertura (TC) y el Índice de Orientación Regional (IOR). Los resultados mostraron que Brasil evolucionó mucho en las exportaciones de arroz y mejoró la competitividad de su producto. A pesar de esto, todavía tiene tasas más bajas que todos los países que se compararon en el estudio.
\end{abstract}

Palabras clave: Agroindustria; Comercio internacional; Cultivo de arroz; Ventaja competitiva.

\title{
1. Introdução
}

O Mercado Comum do Sul (Mercosul) foi criado em 1991 pela Argentina, Brasil, Paraguai e Uruguai e responde por três quartos da economia na América do Sul (Araújo, et al., 2021; Basnet \& Pradhan, 2017). Embora o Brasil entre eles seja um dos países mais desenvolvidos na agricultura, manufatura e no setor de serviços (Basnet \& Pradhan, 2017), o surgimento do Mercosul, fez com que o este importasse mais produtos dos países parceiros por questões logísticas, de preço, diferenças tarifárias e tributárias, entre outros (Ariosti, 2018; Basnet \& Pradhan, 2017).

O arroz, por exemplo, foi um desses produtos. Capitani, et al. (2011) identificou em seu estudo que diversos fatores nos anos da década de 1990, como elevada taxa de juros, fim da garantia de preços mínimos e garantia de compra da produção para estoque afetaram a rentabilidade da produção do arroz no Brasil. Esses fatores ocasionaram o endividamento de diversos produtores, principalmente do Rio Grande do Sul, principal estado produtor e exportador do grão. Capitani, et al. (2011) afirmam ainda que a rentabilidade da produção vem diminuindo no Brasil, os custos da lavoura são muito altos, os preços pagos aos produtores são baixos e, consequentemente, a concorrência desfavorável com países do Mercosul. Souza \& Révillion (2013) corroboram que esta posição ao identificar que em 2010 a cultura do cereal apresentava lucratividade na Argentina e no Uruguai, enquanto observou-se resultados negativos no Brasil e no Paraguai.

Oliviera e Stülp (2011) estudando a influência de políticas tributárias sobre o setor do arroz, considerando o Rio Grande do Sul (RS) no âmbito do Mercosul, e o ano de 2006 e projetando até 2020, identificaram que apenas o fim da guerra fiscal entre os estados brasileiros em relação ao ICMS, fixando em 7\%, poderia trazer uma melhor rentabilidade aos produtores gaúchos. Os autores ainda complementam que dado o cenário do mercado em 2011, somente a alíquota zerada teria efeitos para gerar rentabilidade aos produtores do Rio Grande do Sul.

No ano de 2012, numa tentativa de aumentar a participação do arroz brasileiro no mercado mundial foi instituído o projeto "Brazilian Rice" que teve como objetivo promover o comércio internacional do arroz brasileiro, bem como os seus derivados. O projeto foi realizado por parceria da Associação Brasileira de Indústria do Arroz e da Agência Brasileira de Promoção de Exportações e Investimentos (Abiarrox/Apex-Brasil, 2021). Desde então, tem-se percebido um aumento nos números do comércio externo do cereal. Preços esses que vieram a aumentar significativamente com a desvalorização da moeda brasileira e os impactos da pandemia do Covid-19, que fizeram com os mercados internacionais demandassem mais arroz gerando escassez no mercado interno (Globo Rural, 2021). Dessa maneira, existe uma necessidade de estudos que possam entender a influência da exportação na produção e comercialização brasileira de arroz no mercado interno. Além disso, é necessário que tais estudos considerem também a influência da redução das tarifas provocadas pelo advento do Mercosul. Lacuna esta que visa ser parcialmente preenchida por este estudo.

Observa-se por tanto que o Brasil tem grande potencial para ser um grande exportador de arroz, pois já se destaca pela 
qualidade do grão e tem expandido o seu comércio para diversos destinos. Entretanto, é necessário corrigir diversas questões legais como legislações ambientais mais firmes, correções nos impostos e taxas pagas por produtores e indústria (Portal Agrolink, 2021). Diante desse contexto, o objetivo deste trabalho é avaliar a evolução das exportações de arroz brasileiras e analisar sua competitividade em relação aos países do Mercosul. Este estudo é importante pois visa compreender como o comércio internacional influência cadeias agrícolas, sendo mais especificamente neste caso a cultura do arroz, tão essencial aos brasileiros.

\section{Metodologia}

Tendo como objetivo de avaliar a evolução da exportação de arroz brasileira e comparar com os principais países do Mercosul: Argentina, Paraguai, Uruguai, a metodologia deste trabalho dividiu-se em duas etapas: (i) estudo estatístico descritivo e (ii) estudo de competitividade utilizando-se o Índice de Vantagem Comparativa Revelada (IVCR), Taxa de Cobertura (TC) e o Índice de Orientação Regional (IOR).

Para a primeira etapa foram utilizados dados secundários de volumes de exportação do Brasil durante o período de 22 anos (1997-2018). Os dados foram retirados do sistema de comércio exterior brasileiro (COMEXSTAT), que é o sistema do Ministério da Indústria, Comércio Exterior e Serviços do Brasil (MDIC) e que tem por finalidade a consulta e extração de dados do comércio exterior brasileiro (MDIC, 2019).

O sistema divulga mensalmente dados detalhados das exportações e importações do país que são extraídos do SISCOMEX, sistema do Programa Portal Único de Comércio Exterior, e são baseados em todos as trocas declaradas dos importadores e exportadores. Para a busca no sistema, foi utilizado o número 1006 do sistema harmonizado (SH4) que é a classificação do arroz. Após a coleta, foi utilizado o software Microsoft Excel v.16 ${ }^{\circledR}$ para organizar e criar os gráficos para uma melhor visualização dos dados e para realizar as análises estatísticas.

Ainda no estudo estatístico descritivo para comparação entre as exportações entre os quatro países obteve-se os volumes de exportação no site Trade Map ${ }^{\circledR}$ (Trade Map, 2019). O Trade Map é um sistema que foi desenvolvido pelo International Trade Centre UNCTAD/WTO (ITC). Os dados anuais são retirados principalmente do UN Comtrade que é o maior banco de dados mundial de estatísticas do comércio, mantido pela United Nations Statistics Division (UNSD). Nesta análise os dados referemse ao período de 2001 a 2018 que era o período disponível dentro da plataforma no momento da realização do presente estudo.

Ainda em relação a coleta de dados, foram obtidos os volumes de produção brasileira de arroz junto a Companhia Nacional de Abastecimento (Conab, 2019). Embora estes sejam disponibilizados desde 1976 optou-se para efeito de comparação das exportações manter o mesmo período que foi obtido junto ao COMEXSTAT, 1997-2018.

Para a segunda etapa da pesquisa, o estudo de competitividade frente aos principais países produtores de arroz do bloco do Mercosul (Argentina, Paraguai e Uruguai), foram utilizados os itens já mencionados: IVCR, TC e o IOR.

O IVCR foi proposto por Balassa (1965) e determinado conforme a equação (1):

$$
\operatorname{IVCRi} i_{j}=\left(x i_{j} / x_{j}\right) /\left(x i_{z} / x_{z}\right)
$$

Onde,

$\mathrm{IVCRi}_{\mathrm{j}}=$ Índice de vantagem comparativa revelada do produto $i$ do país $j$

$\mathrm{xi}_{\mathrm{j}}=$ Valor das exportações do produto $(i)$ do país $(j)$;

$\mathrm{x}_{\mathrm{j}}=$ Valor das exportações totais do país $(j)$; 
$\mathrm{xi}_{\mathrm{z}}=$ Valor das exportações mundiais $(z)$ do produto $(i)$

$\mathrm{x}_{\mathrm{z}}=$ Valor das exportações mundiais $(\mathrm{z})$ totais.

$\mathrm{O}$ indicador pode variar de zero a infinito. Se o $I V C R_{j}>1$, o país apresenta uma vantagem comparativa revelada para as exportações do produto analisado. Caso o $\mathrm{IVCR}_{\mathrm{j}}<1$, há uma desvantagem comparativa revelada para as exportações do produto analisado. Segundo Hidalgo, et al. (2004) o IVCR se caracteriza como uma medida revelada, visto que para realizar o seu cálculo são utilizados os dados pós comércio.

O índice é um dos métodos mais utilizados para determinar os níveis de competitividade de um país. A partir dos resultados obtidos, é possível analisar o desempenho relativo das exportações de qualquer categoria de produtos. Com os valores encontrados, é possível identificar os padrões de comércio existentes, porém, não é possível identificar se esses padrões se encaixam em situações ótimas ou não. O motivo é pelo fato de o índice não considerar a presença de distorções que ocorrem na economia, bem como barreiras tarifárias, subsídios, acordos entre comércios, fatores cambiais e outros que podem provocar alterações nos resultados encontrados.

O segundo índice utilizado, TC, é calculado conforme a equação (2);

$$
T C i_{j}=\frac{X i_{j}}{M i_{j}}
$$

Onde,

$\mathrm{TCi}_{\mathrm{j}}=$ Taxa de cobertura;

$\mathrm{Xi}_{\mathrm{j}}=$ Exportações do produto $i$ do país $j$;

$\mathrm{Mi}_{\mathrm{j}}=$ Importações do produto $i$ do país $j$.

Conforme determina Bittencourt, et al. (2012), a taxa de cobertura é utilizada para correlacionar as exportações e importações de um determinado produto. Com o cálculo, é possível obter e analisar resultados que embasam os estudos sobre competitividade. Se o valor encontrado de $\mathrm{TC}_{\mathrm{j}}>1$ pode-se dizer que o produto tem uma vantagem comparativa das exportações perante a cobertura das importações. Se a $\mathrm{TCi}_{\mathrm{j}}<1$ significa que as importações do produto $i$ foram maiores que as exportações. Com esse indicador é possível verificar se o produto i apresentou déficit ou superávit para a balança comercial da região $j$.

O último índice, o IOR, é calculado através da equação (3) da seguinte forma:

$$
I O R_{j}=\left(X_{r j} / X_{t r}\right) /\left(X_{o j} / X_{t o}\right)
$$

Onde,

IORj = Índice de orientação regional de arroz;

Xrj = Valor das exportações do Brasil de arroz para o país j;

Xtr $=$ Valor total das exportações do Brasil para o país j;

Xoj = Valor das exportações do Brasil de arroz extra-país j;

Xto = Valor total das exportações do Brasil extra-país j;

Segundo Yeats (1998), o valor encontrado aplicando-se o IOR pode ser entre 0 e infinito. Encontrando-se o valor igual a 1 mostra que a tendência de exportar tanto para dentro como para fora do bloco é a mesma. Se ao longo do período analisado 
os resultados forem crescentes, indicará que há uma tendência a ter mais exportação para dentro do bloco. De outro lado, se os valores forem decrescentes, mostrará que a direção das exportações está sendo para fora do Bloco.

\section{Resultados e Discussão}

\subsection{Produção brasileira de arroz e as exportações do país}

A Figura 1 mostra a produção de arroz e a evolução das exportações entre 1997 e 2018.

Figura 1 - Quantidade de arroz produzido e exportado no Brasil (1976-2018).

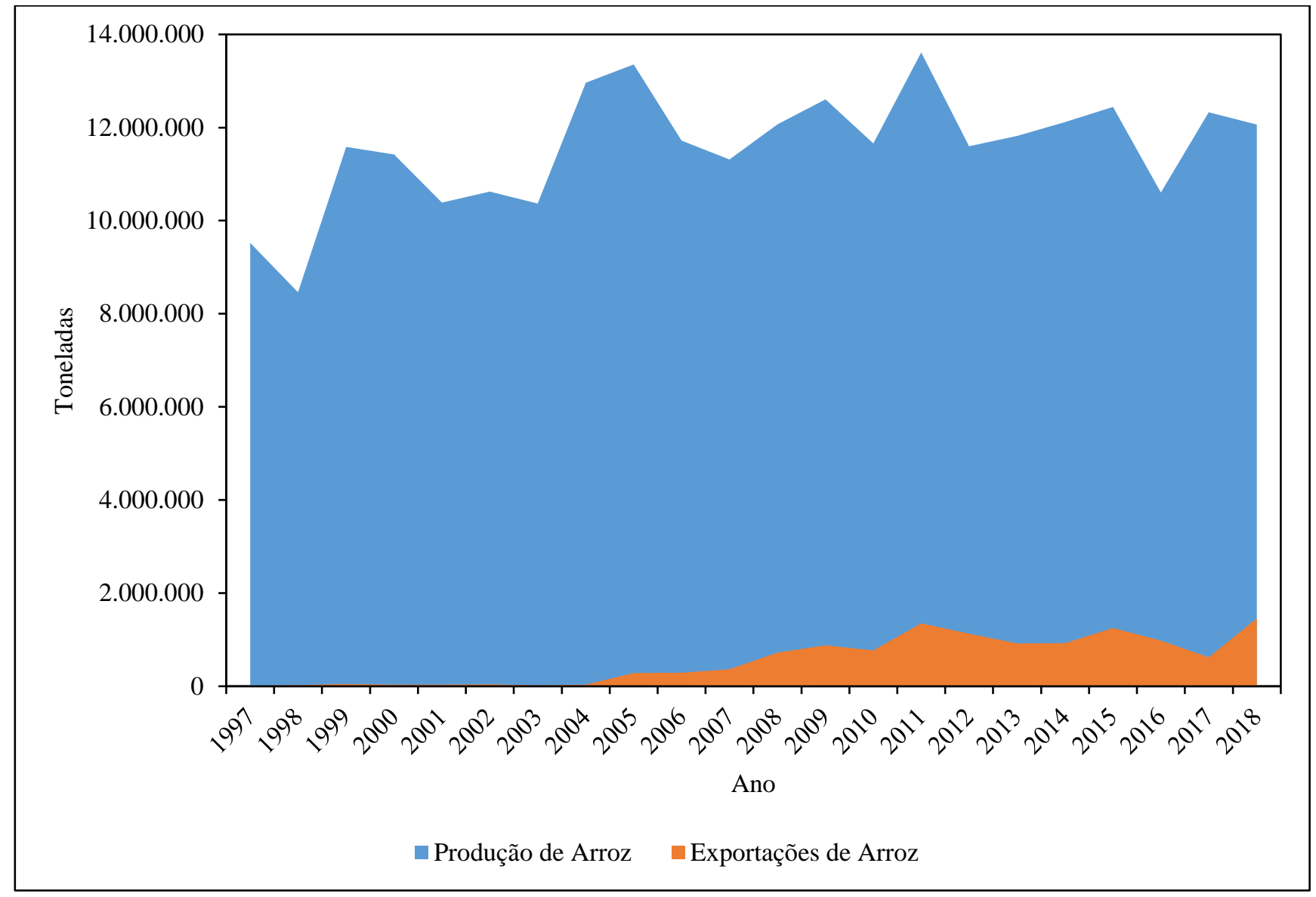

Fonte: Autores, com dados das Estatísticas de Comércio Exterior do Brasil e da Companhia Nacional de Abastecimento (Conab, 2019 e MDIC, 2019).

A produção brasileira em geral visa atender o mercado interno, mas a partir de 2004 nota-se que o país começou a exportar cada vez mais quantidades. No ano de 2011 foram 1.348.944,6 toneladas (9,9\% da sua produção total) e no ano de 2018 essa quantidade foi de 1.458.676,4 toneladas (12.1\% da sua produção total). Wander (2006), observa que até 2003/2004 o Brasil não tinha autossuficiência de produção de arroz necessitando de importações. Esta autossuficiência alcançada pode ter sido a razão do início das exportações do país. Até o ano de 2004, a quantidade exportada sempre foi abaixo de 37.000 toneladas. Do ano de 2004 para o ano de 2005 houve um aumento de cerca de 672\% conforme observado nos dados obtidos do MDIC (2019).

Zanin e Bachi (2017) afirmam que o crescimento das exportações brasileiras de arroz é um fenômeno recente e devese a estagnação do mercado interno desde 2000 enquanto a produtividade entre 2000 e 2015 cresceu $4 \%$ ao ano. Esse aumento ocorreu devido alguns principais continentes que tem sido destino do arroz brasileiro: a América do Sul, a América Central e a África. O que se observa é a venda do arroz brasileiro para países de baixa renda o que explica o perfil dessas exportações entre 
2014-2016, por exemplo, que foram compostas por: beneficiado (36\%), quebrado (33\%) e com casca (29\%) (Zanin \& Bachi, 2017). As exportações brasileiras por continente podem ser observadas na Figura 2.

Figura 2 - Exportação de brasileira de arroz por continente (1997-2018).

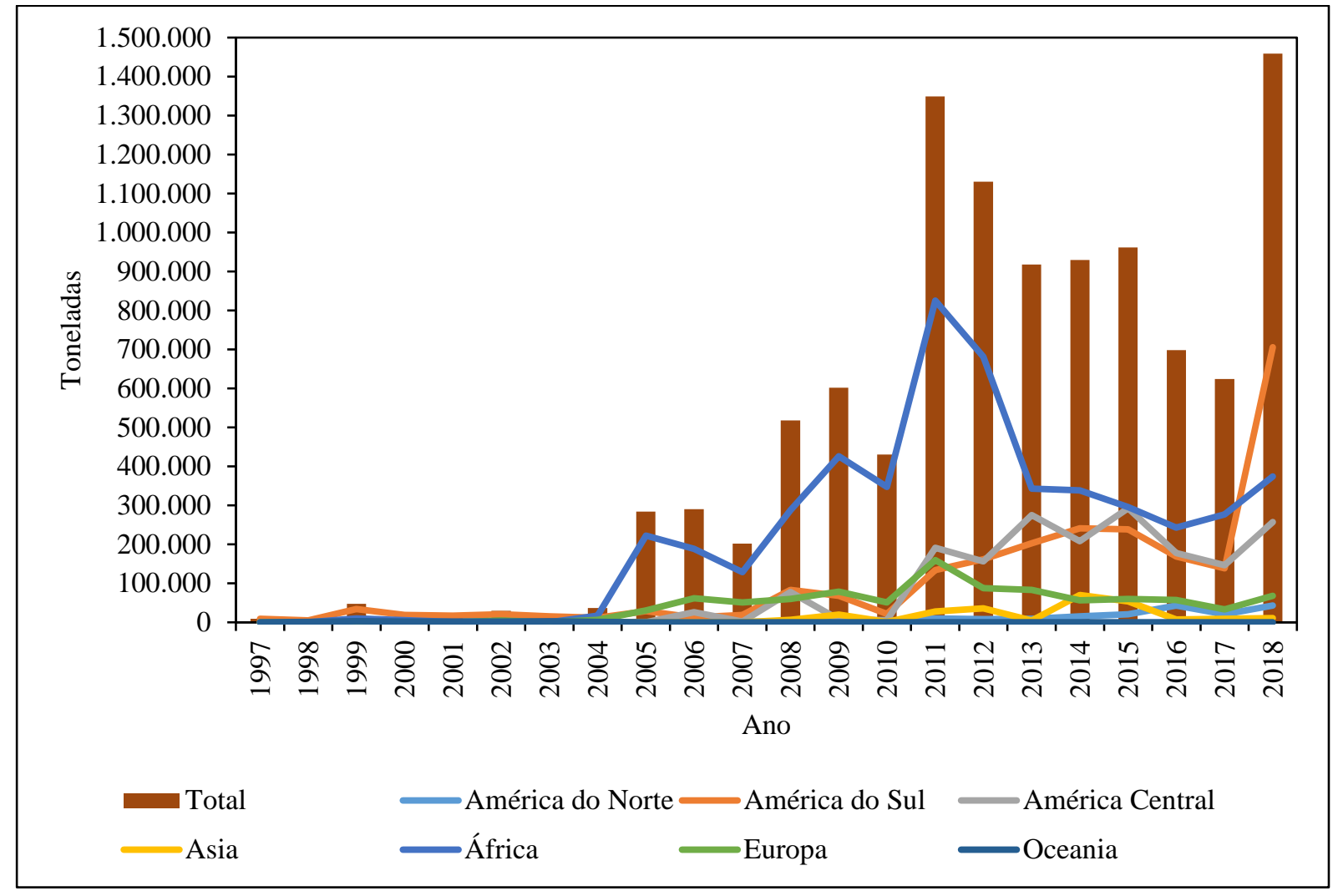

Fonte: Autores, com dados das Estatísticas de Comércio Exterior do Brasil (MDIC, 2019).

Os resultados deste trabalho demonstraram que nos anos de 2011, 2012 e 2018 houve aumento significativo das exportações do arroz brasileiro. Nos anos de 2011 e 2012 esse aumento foi em consequência, principalmente, do aumento das exportações para a Nigéria e outros países da África impulsionado, em parte, devido aos leilões de Prêmio para Escoamento de Produtos (PEP) que é realizado pelo governo (Instituto Rio Grandense do Arroz [IRGA], 2011). Até o mês de setembro do ano de 2011 já haviam ocorrido 16 leilões de PEP para o Brasil (IRGA, 2011). O país tinha uma oferta de 2,1 milhão de toneladas e 1,4 milhão de toneladas já haviam sido negociados (IRGA, 2011). O projeto "Brazilian Rice” também contribuiu para este aumento, principalmente com a participação em feiras internacionais que visaram promover o comércio do grão brasileiro (Marques, et al., 2014).

Já no ano de 2018, o aumento significativo foi por conta do aumento da exportação de arroz para a Venezuela. De acordo com Dib (2018) o grande aumento, entre diversos fatores, deveu-se a operações comerciais via Tradings Internacionais que garantem o pagamento do arroz brasileiro enviado para a Venezuela. Tais Tradings pagam os exportadores, que recebem em troca petróleo Venezuelano e que, posteriormente, é enviado para a China. A Figura 3 apresenta os volumes exportados por país importador. 
Research, Society and Development, v. 10, n. 13, e195101321043, 2021

(CC BY 4.0) | ISSN 2525-3409 | DOI: http://dx.doi.org/10.33448/rsd-v10i13.21043

Figura 3 - Países que o Brasil mais exportou arroz durante o período analisado (1997-2018).

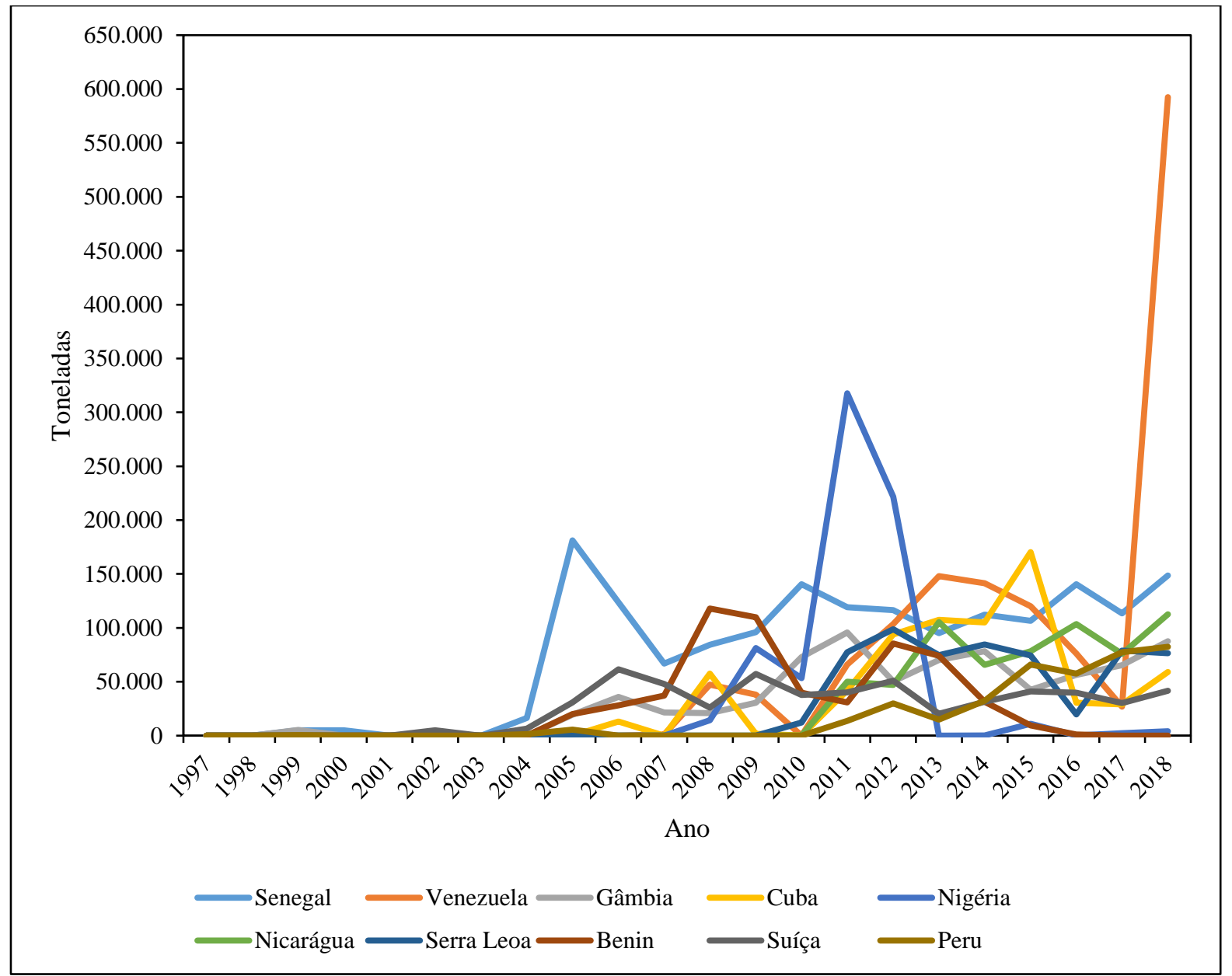

Fonte: Autores, com dados das Estatísticas de Comércio Exterior do Brasil (MDIC, 2019).

Analisando-se do ponto de vista interno brasileiro, a região que mais exporta arroz é a região Sul, como pode ser visto na Figura 4. 
Figura 4 - Principais estados brasileiros exportadores de arroz (1997-2018).

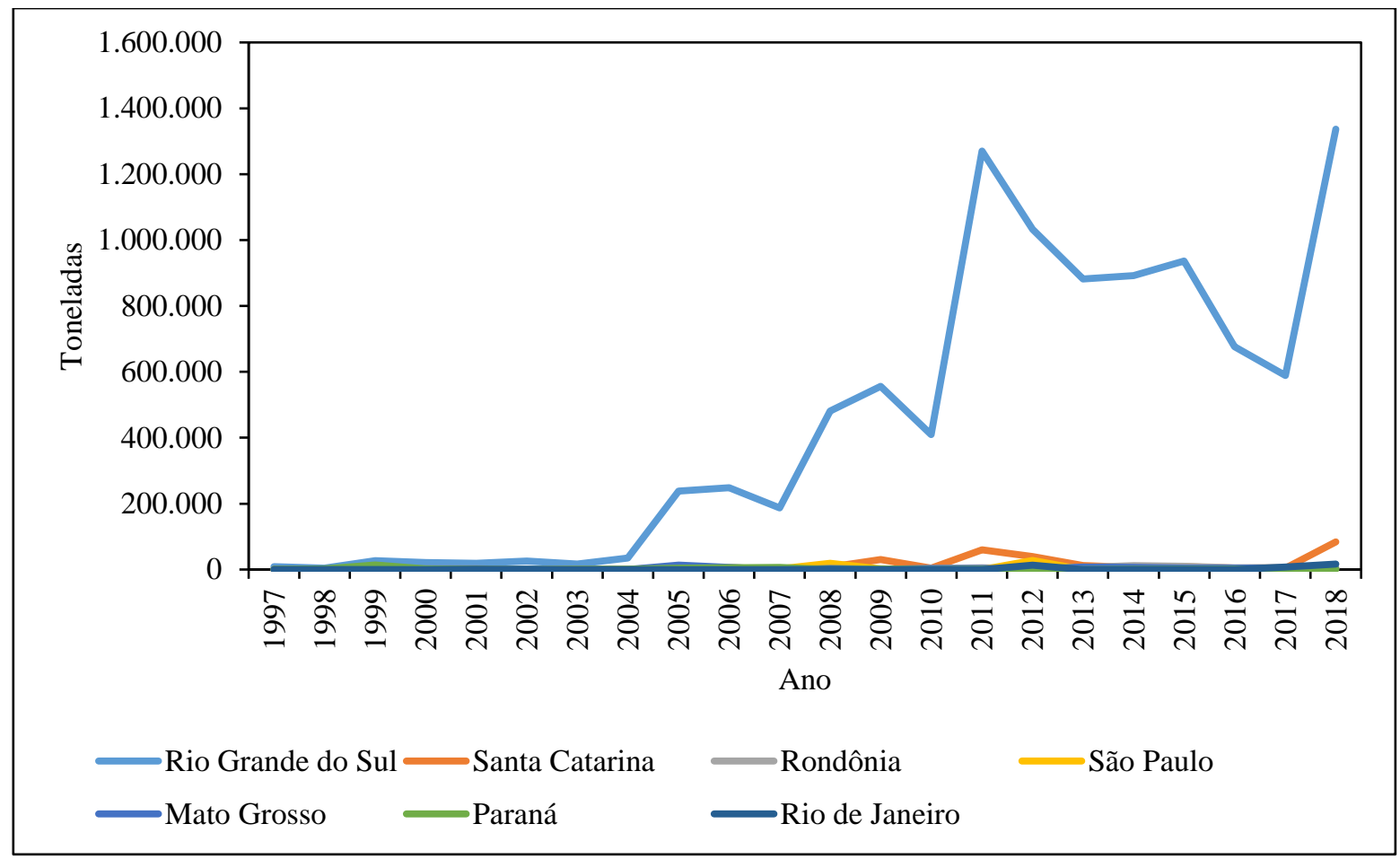

Fonte: Autores, com dados das Estatísticas de Comércio Exterior do Brasil (MDIC, 2019).

O estado do Rio Grande do Sul tem destaque já que é também o maior produtor do grão no país. Dentro do período analisado, cerca de $93,4 \%$ de todo o arroz brasileiro que foi exportado foi de origem gaúcha. Esse mesmo resultado foi registrado por Zanin e Bachi (2017) que entre 2009 e 2016 identificaram um volume de 95\% das exportações originárias do Rio Grande do Sul. Miranda, et al. (2007) que o Estado é o ponto inicial para identificar os principais elementos de formação do preço no arroz no mercado doméstico, o papel das exportações e as possibilidades de exportação.

\subsection{Panorama da produção e exportação do Brasil, Argentina, Uruguai e Paraguai (2001-2018)}

A Figura 5 mostra a produção de arroz do Brasil, Paraguai, Uruguai e Argentina entre o período de 2001 a 2018 . Entre os países analisados, o Brasil sempre foi o maior produtor do grão em termos de quantidade. Embora o país seja o maior produtor, deve-se levar em conta que a sua população é superior aos demais. Além de ser superior, a população brasileira é grande consumidora do grão, sendo o consumo muito maior também que entre os países comparados. Isso faz com que o Brasil não só exporte, mas importe desses países para manter os preços em patamares mais baixos, uma vez que o produto vindo do Mercosul tem preços bastante competitivos (Miranda, et al., 2007). O Brasil consume cerca de 95\% da produção da Argentina e Uruguai (Marion Filho \& Einloft, 2008). 
Figura 5 - Produção de Arroz do Brasil, Paraguai Uruguai e Argentina (2001-2018).

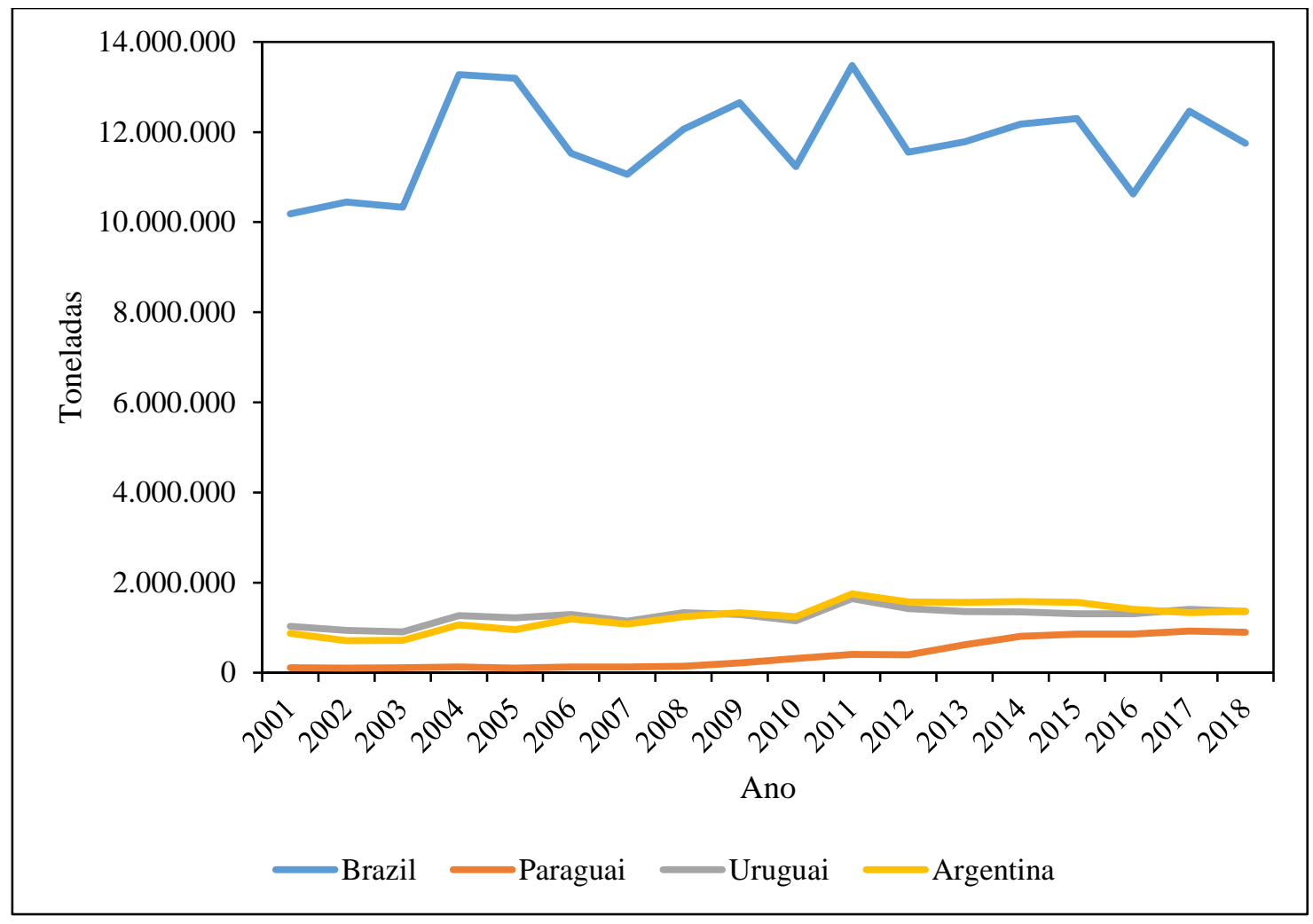

Fonte: Autores, com base em Trade Map (2019).

A Figura 6 mostra a quantidade em toneladas exportada pelo Brasil, Paraguai, Uruguai e Argentina. O Brasil, dentro do período analisado, teve bastante altas e quedas. No ano de 2018, teve a maior quantidade do período e a maior também entre os países, cerca de 1.460 .000 toneladas. Um fator importante por essa elevação é a taxa de câmbio, segundo o estudo de Zanin \& Bachi (2017) uma elevação em 1\% nesta taxa faz com que as vendas externas aumentem 3,78\%. Entretanto, no Mercosul, a Argentina é o país mais eficiente na produção, sendo mais competitivo em termos de custo por hectare, seguido por Uruguai, demonstrando a falta de vantagem comparativa do Brasil na produção e exportação de arroz (Lima, et al., 2016). 
Figura 6 - Quantidade de arroz exportada pelo Brasil, Paraguai, Uruguai e Argentina (2001-2018).

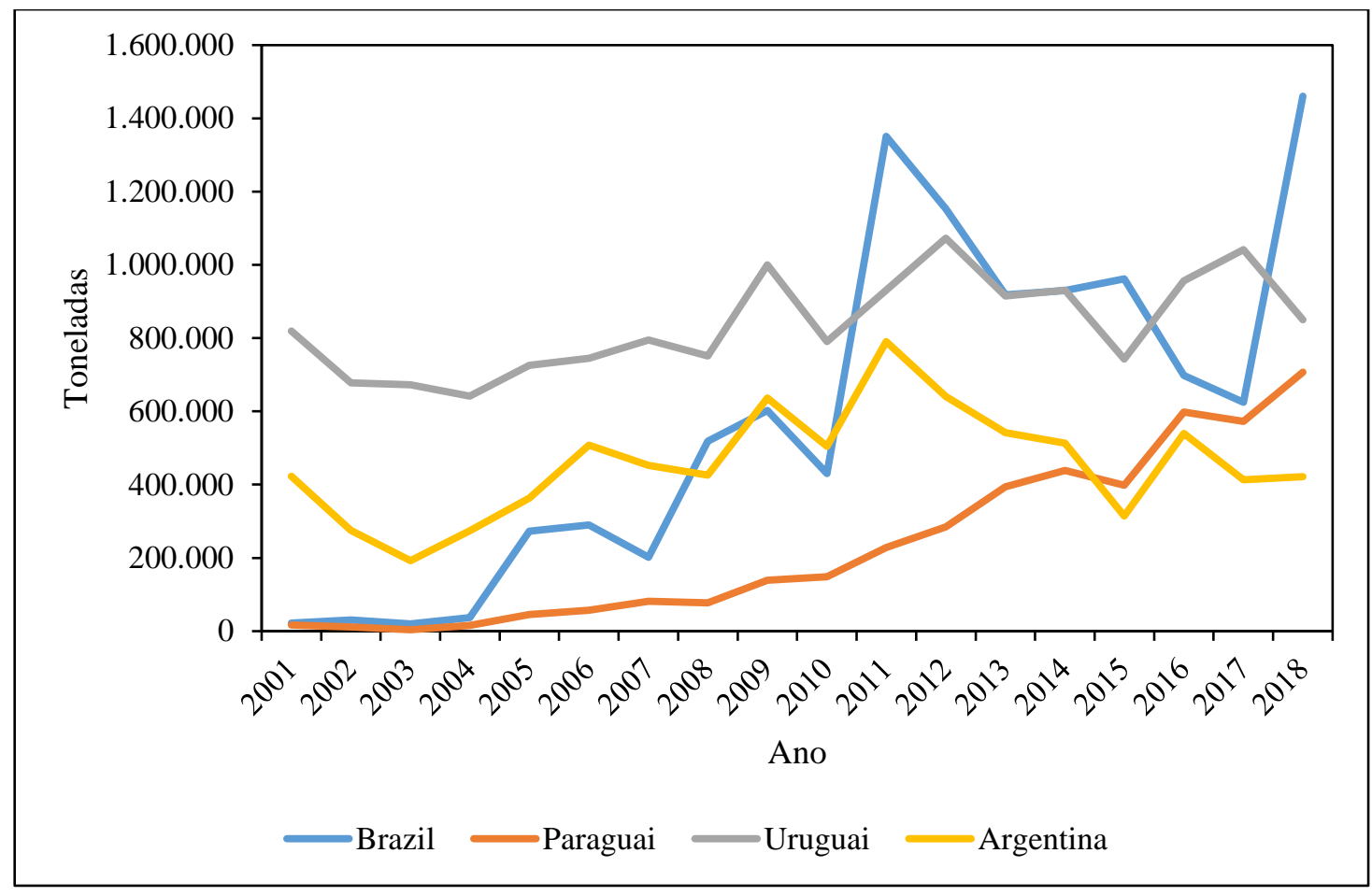

Fonte: Autores, com base em Trade Map (2019).

Paraguai foi o único país que teve um crescimento constante ao longo do período. No início do período o país quase não exportava, mas aos poucos foi ganhando mercado e o Brasil foi um dos países que começou a comprar o produto paraguaio. No ano de 2018, os dados do Trade Map (2019) demonstram que o Paraguai exportou 79,03\% do total que produziu e foi a maior quantidade também, cerca de 707.010 toneladas. O Uruguai também é um país de exporta muito do que produz. A média da quantidade exportada em relação a produção foi de $66,76 \%$ ao longo do período. O ano que o Uruguai mais exportou em termo de quantidade foi no ano de 2012, cerca de 1.072,894 toneladas segundo os dados do Trade Map (2019).

A Argentina também exporta boa parte do que produz. A média de exportação frente a produção foi de $36,59 \%$ de 2001 a 2018. O ano que o país mais exportou foi no ano de 2011, cerca de 790.500 toneladas (Trade Map, 2019). Segundo Marion Filho e Einloft (2008) o custo de produção de arroz na Argentina representa 66,96\% do praticado no Brasil e 80,10\% do praticado no Uruguai.

\subsection{Análise da competitividade do arroz brasileiro}

\subsection{1 Índice de Vantagem Comparativa Revelada (IVCR)}

O IVCR permitiu verificar o comportamento das exportações brasileiras de arroz ao longo dos últimos anos. Além de realizar essa verificação, também foi possível visualizar a vantagem brasileira frente aos índices de países do Mercosul, considerados seus principais concorrentes. A Tabela 1 mostra os índices do Brasil, Paraguai, Argentina e Uruguai. 
Tabela 1 - Índice de Vantagem Comparativa Revelada (IVCR).

\begin{tabular}{ccccc}
\hline Ano & Brasil & Paraguai & Argentina & Uruguai \\
\hline 2001 & 0,09 & 0,74 & 2,62 & 74,36 \\
2002 & 0,10 & 0,64 & 1,83 & 74,36 \\
2003 & 0,07 & 0,42 & 1,96 & 87,77 \\
2004 & 0,08 & 1,21 & 2,25 & 64,52 \\
2005 & 0,49 & 2,56 & 2,30 & 60,10 \\
2006 & 0,49 & 3,80 & 3,31 & 61,96 \\
2007 & 0,35 & 4,64 & 2,79 & 64,87 \\
2008 & 1,18 & 4,53 & 2,53 & 55,84 \\
2009 & 1,12 & 6,12 & 3,14 & 54,55 \\
2010 & 0,60 & 7,20 & 2,56 & 42,82 \\
2011 & 1,78 & 8,12 & 3,23 & 44,26 \\
2012 & 1,72 & 12,35 & 2,89 & 49,09 \\
2013 & 1,22 & 12,84 & 2,81 & 41,14 \\
2014 & 1,26 & 13,15 & 2,88 & 39,96 \\
2015 & 1,29 & 11,01 & 1,94 & 33,29 \\
2016 & 1,04 & 17,65 & 2,81 & 45,49 \\
2017 & 0,80 & 15,89 & 2,19 & 41,40 \\
2018 & 1,44 & 17,84 & 1,77 & 38,53 \\
\hline Média & 0,84 & 7,82 & 2,55 & 54,13 \\
\hline
\end{tabular}

Fonte: Autores, com base em Trade Map (2019).

Como um país só apresenta vantagem comparativa revelada se o valor encontrado for maior que 1 (Hidalgo, et al., 2004), pode-se notar que até o ano de 2008, o Brasil não tinha tido nenhuma vantagem. A partir do ano de 2008, exceto nos anos de 2010 e 2017, o país apresentou uma vantagem comparativa revelada na exportação do arroz. Este cenário mostra que o Brasil, apesar de ter o índice baixo quando comparado aos outros países, vem mudando em relação ao comércio internacional de arroz.

O Paraguai até o ano de 2004 também não apresentou nenhuma vantagem. Após o ano de 2005, o país começou a apresentar vantagem e o índice cresceu ano após ano. Dos quatro países analisados, o Paraguai foi o que teve o maior aumento do seu índice.

A Argentina e o Uruguai, apesar de nunca terem apresentado desvantagem comparativa revelada, não tiveram crescimento dos seus índices ao longo do período analisado. A Argentina teve os seus índices bastante variáveis, com altas e quedas ao longo dos anos. Já o Uruguai, no início, pode-se verificar que o valor do seu índice era bastante alto comparado ao dos outros países. Entretanto, o índice vem apresentando quedas ao longo do período. Apesar destas quedas, no ano de 2018 o resultado encontrado para o Uruguai ainda foi mais alto que o valor encontrado para os outros países. De acordo com Marion Filho e Einloft (2008) o Uruguai pratica uma política agrícola com valorização do produto voltado para a exportação que explica o sucesso na produção de arroz.

\subsubsection{Taxa de Cobertura (TC)}

A Tabela 2 mostra a Taxa de Cobertura do Brasil, Paraguai, Argentina e Uruguai. Como o resultado mostra a fração das exportações sobre as importações, nota-se que até o ano de 2007 as importações se sobrepuseram sobre as exportações. A partir 
de 2008, apesar de alguns anos as importações terem sido mais altas (anos de 2009, 2010, 2016 e 2017), as exportações começaram a aumentar e foram maiores que as importações o que correlaciona ao trabalho de Zanin e Bach (2017).

Tabela 2 - Taxa de Cobertura (TC).

\begin{tabular}{ccccc}
\hline Ano & TC Brasil & TC Paraguai & TC Argentina & TC Uruguai \\
\hline 2001 & 0,04 & 1,68 & 23,86 & 5595,73 \\
2002 & 0,05 & 1,27 & 18,54 & 545,59 \\
2003 & 0,02 & 2,52 & 11,09 & 225,96 \\
2004 & 0,03 & 6,58 & 21,54 & 1541,91 \\
2005 & 0,44 & 32,02 & 36,73 & 2993,51 \\
2006 & 0,34 & 31,13 & 69,08 & 1321,08 \\
2007 & 0,23 & 48,75 & 35,77 & 903,26 \\
2008 & 1,38 & 48,87 & 42,98 & 1953,72 \\
2009 & 0,98 & 92,84 & 61,53 & 717,25 \\
2010 & 0,43 & 93,56 & 45,52 & 297,64 \\
2011 & 2,24 & 93,21 & 66,17 & 257,81 \\
2012 & 1,60 & 147,84 & 70,92 & 410,31 \\
2013 & 1,07 & 159,02 & 70,65 & 170,93 \\
2014 & 1,32 & 146,03 & 66,80 & 199,11 \\
2015 & 2,22 & 117,70 & 35,34 & 669,29 \\
2016 & 0,87 & 149,40 & 43,88 & 197,45 \\
2017 & 0,76 & 171,82 & 36,69 & 183,74 \\
2018 & 2,15 & 219,44 & 38,34 & 467,48 \\
\hline Média & 0,90 & 86,87 & 44,19 & 1036,21 \\
\hline
\end{tabular}

Fonte: Autores, com base em Trade Map (2019).

Entre os anos analisados, o Paraguai se mostrou como um país exportador de arroz. No ano de 2001, a diferença entre exportação e importação não era tão expressiva. Com o passar dos anos a TC foi aumentando ano a ano. No ano de 2018 as exportações chegaram a ser 219,44 vezes a mais do que as importações o que mostra que o comércio de arroz tem sido cada vez mais importante para a balança comercial do país. Isso até pouco tempo era difícil de supor e Capitani, et al. (2011) afirmava que a produção e exportações do Paraguai tinham pouca relevância no contexto do Mercosul.

A Argentina também tem a balança comercial favorável para o comércio de arroz. Embora a TC do país tenha variado bastante, o comércio do grão se mostrou importante em todo o período em especial nos anos de 2006, 2012 e 2013 em que as TCs foram próximo a 70. De acordo com Oliveira e Stülp (2011) o arroz agulhinha que tem custos de produção menores e alta qualidade, alinhado aos fretes e os custos de comercialização menores que os do Brasil, associada a uma taxa de câmbio favorável, fez com que à expansão da produção do arroz argentino acontecesse visando o mercado brasileiro.

Analisando a TC do Uruguai, nota-se que o país é um grande exportador de arroz. O arroz contribui grandemente para a balança comercial. No ano de 2001 o valor exportado foi 5595,73 vezes a mais do que o valor importado. A diferença entre a exportação e a importação tem diminuído ao longo dos anos. Entretanto, mesmo com tal diminuição, no ano de 2018, o valor encontrado da TC para o Uruguai foi bem maior que nos outros países. O Uruguai tem trabalhado tem trabalhado na 
diversificação e qualidade de seu arroz, na abertura de novos mercados, nas articulações institucionais entre produtores, indústrias beneficiadoras e distribuidoras do cereal junto ao governo local o que tem refletido nos resultados (Capitani, et al. 2011).

\subsection{3 Índice de Orientação Regional (IOR)}

O índice de Orientação Regional (IOR) mostra se as exportações de um país estão orientadas para o bloco/país em que está sendo verificado. A Tabela 3 mostra que o Brasil não teve crescimento do índice para nenhum dos 3 países do Mercosul. Este comportamento indica que, apesar do arroz ter uma Vantagem Comparativa Revelada observa que a partir do ano de 2008, a orientação do arroz brasileiro está sendo em direção a outros mercados.

Tabela 3 - Índice de Orientação Regional (IOR).

\begin{tabular}{lccc}
\hline Ano & Brasil-Agentina & Brasil-Paraguai & Brasil-Uruguai \\
\hline 2001 & 2,06 & 10,30 & 0,00 \\
2002 & 2,04 & 9,23 & 0,00 \\
2003 & 6,12 & 7,57 & 0,00 \\
2004 & 0,88 & 6,64 & 0,39 \\
2005 & 0,07 & 0,64 & 0,07 \\
2006 & 0,06 & 0,58 & 0,03 \\
2007 & 0,29 & 0,61 & 0,00 \\
2008 & 0,08 & 0,14 & 0,02 \\
2009 & 0,05 & 0,12 & 0,02 \\
2010 & 0,08 & 0,21 & 0,05 \\
2011 & 0,04 & 0,06 & 0,12 \\
2012 & 0,03 & 0,08 & 0,11 \\
2013 & 0,02 & 0,10 & 0,26 \\
2014 & 0,02 & 0,08 & 0,05 \\
2015 & 0,02 & 0,08 & 0,04 \\
2016 & 0,01 & 0,22 & 0,31 \\
2017 & 0,00 & 0,11 & 0,11 \\
2018 & 0,00 & 0,04 & 0,01 \\
2019 & 0,01 & 0,06 & 0,18 \\
\hline Média & 0,62 & 1,94 & 0,09 \\
\hline & & 0 & \\
\hline
\end{tabular}

Fonte: Autores com base em Trade Map (2019).

Baseando-se nas afirmações de Yeats (1998) pode-se evidenciar que o arroz brasileiro tem pouca viabilidade dentro do bloco, indicando que as exportações tem destino a outras regiões conforme apresentado no trabalho de Zanin \& Bach (2017). Ao mesmo tempo confirma a falta de competitividade do arroz brasileiro dentro do Mercosul em relação aos países vizinhos como demonstrado nos trabalhos de Marion Filho e Einloft (2008), Oliveira e Stülp (2011) e Capitani, et al. (2011).

\section{Conclusão}

O presente estudo faz uma avaliação das exportações brasileiras de arroz e compara o seu comportamento aos principais 
países do Mercosul: Argentina, Paraguai e Uruguai. Os resultados demonstram que o arroz produzido na Argentina e Uruguai são mais competitivos e se direcionam principalmente ao mercado brasileiro. O Brasil por sua vez obteve autossuficiência na sua produção de arroz após 2004 e utiliza o produto importado que chega de forma mais competitiva devido aos acordos do bloco para regular os preços internos. Por sua vez, isso faz com que haja necessidade de exportar o excedente do arroz produzido no país.

O Brasil sempre foi um grande produtor e consumidor de arroz, mas aos poucos tem aumentado e melhorado a qualidade do seu produto e vendido no comércio internacional, principalmente a países da América Central e África. Entretanto, para o país consolidar uma maior participação no mercado internacional, é necessário realizar melhorias em diversas etapas, desde a produção, até o comércio do produto para ser mais competitivo internacionalmente. Entre os países comparados neste estudo, o Brasil é o que possui valores de arrendamento da terra e de água mais altos. As principais queixas dos produtores são as taxas desleais, taxas cambiais, preços de matéria-prima muito alta, dificuldade logísticas, falta de incentivos, créditos.

Apesar da concorrência, o país deve definir estratégias conjuntas com os países do Mercosul que também exportam arroz para conquistar novos mercados. Assim, é possível obter melhores resultados não apenas para o país, mas para o bloco econômico como um todo.

Como trabalhos futuros sugere-se uma comparação dos mercados internos e externos brasileiros de arroz para avaliar a influência de um no outro e analisar o que seria mais viável para os produtores atenderem considerando demanda e valor perpétuo do mercado.

\section{Agradecimentos}

Ao Programa de Pós-Graduação em Agronegócios da Universidade Federal da Grande Dourados e a Coordenação de Aperfeiçoamento de Pessoal de Nível Superior.

\section{Referências}

Abiarrox/Apex-Brasil. (2021). Brazilian Rice. http://brazilianrice.com.br/en/

Araújo, I. F. de, Perobelli, F. S., \& Faria, W. R. (2021). Regional and global patterns of participation in value chains: Evidence from Brazil. International Economics, 165, 154-171. https://doi.org/10.1016/j.inteco.2020.12.009

Ariosti, A. (2018). Mercosur legislation on food Contact Materials. In Reference Module in Food Science, 18, 1-19. https://doi.org/10.1016/B978-0-08-100596$5.21879-9$

Balassa, B. (1965). Trade liberalisation and "revealed" comparative advantage. The Manchester School, 33(2), 99-123. https://doi.org/10.1111/j.14679957.1965.tb00050.x

Basnet, H. C., \& Pradhan, G. (2017). Regional economic integration in Mercosur: The role of real and financial sectors. Review of Development Finance, 7(2), 107-119. https://doi.org/10.1016/j.rdf.2017.05.001

Bittencourt, G. M., Fontes, R. M. O., \& Campos, A. C. (2012). Determinantes das exportações brasileiras de etanol. Revista de Política Agrícola, 21(4), 4-19. https://seer.sede.embrapa.br/index.php/RPA/article/view/262

Capitani, D. H. D., Miranda, S. H. G. de, \& Filho, J. G. M. (2011). Revista de Economia e Sociologia Rural, 49(3), 545-572. https://doi.org/10.1590/S010320032011000300002

Companhia Nacional de Abastecimento. (2021). Séries Históricas Safra. https://www.conab.gov.br/info-agro/safras/serie-historica-das-safras?start=10.

Dib, A. C. (2018). Exportações de arroz sobem 155,6\% no ano, puxadas por forte aumento nas vendas para Venezuela. https://www.comexdobrasil.com/exportacoes-de-arroz-sobem-1556-no-ano-puxadas-por-forte-aumento-nas-vendas-para-venezuela/

Globo Rural. (2021). Preço do arroz deve se manter elevado, mesmo com Brasil exportando menos. https://revistagloborural.globo.com/Not icias/Agricultura/Arroz/noticia/2021/04/preco-do-arroz-deve-se-manter-elevado-mesmo-com-brasil-exportando-menos.html

Hidalgo, Á., Ferreira, D., \& Gonçalves, P. (2004). Competitividade e Vantagens Comparativas do Nordeste Brasileiro e do Estado de Pernambuco no Comércio Internacional. Anais Do Fórum BNB de Desenvolvimento. Fórum BNB de Desenvolvimento, Fortaleza.

Instituto Rio Grandense do Arroz. (2011). Exportações de arroz alcançam recorde histórico em setembro. IRGA. https://irga.rs.gov.br/exportacoes-de-arrozalcancam-recorde-historico-em-setembro 
Research, Society and Development, v. 10, n. 13, e195101321043, 2021

(CC BY 4.0) | ISSN 2525-3409 | DOI: http://dx.doi.org/10.33448/rsd-v10i13.21043

Lima, V. M. A., Kodama, A. K., Druciaki, F. P., \& Piacenti, C. A. (2016). Análise Econométrica da Demanda de Arroz Importado do Mercosul entre 1997 a 2012. Orbis Latina, 6(1), 24-36. https://revistas.unila.edu.br/orbis/article/view/527Marion Filho, P. J. M., \& Einloft, N. E. (2008). A competitividade do arroz irrigado brasileiro no Mercosul. Organizações Rurais \& Agroindustriais, 10(1), 11-22. http://www.revista.dae.ufla.br/index.php/ora/article/view/88

Marques, A. B. R., Giovane Silveira da, S., \& Claudia Vera da, S. (2014). Efeito da taxa de câmbio sobre a exportação de arroz: Uma análise por meio de modelo econométrico dinâmico. Apresentado no ENEPEX. Encontro de Ensino Pesquisa e Extensão, Dourados.

Ministério da Indústria, Comércio Exterior e Serviços. (2019). Comexstat. http://comexstat.mdic.gov.br/cpt/home

Miranda, S. H. G. de, Souza e Silva, G., Maria Aparecida Serigatto Braghetta, M., \& Esposito, H. (2007). O sistema agroindustrial do arroz no Rio Grande Do Sul. Conhecimentos Para Agricultura Do Futuro. Apresentado no XLV Congresso da Sober, Londrina.

Oliveira, C. F. de, \& Stülp, V. J. (2011). O impacto de políticas tributárias sobre o arroz do Rio Grande do Sul no contexto do Mercosul. Revista de Economia e Sociologia Rural, 49, 647-679. https://doi.org/10.1590/S0103-20032011000300006

Portal Agrolink. (2021). Mercado mundial sinaliza oportunidade de exportação para o arroz brasileiro. https://www.agrolink.com.br/noticias/mercadomundial-sinaliza-oportunidade-de-exportacao-para-o-arroz-brasileiro_407549.html

Trade Map (2019). Trade Map-Trade statistics for international business development. https://www.trademap.org/Index.aspx

Souza, Â. R. L. de, \& Révillion, J. P. P. (2013). Rice production in Mercosur seen through a Policy Analysis Matrix (PAM). Revista de Politica Agricola, 22(1), 55-71. https://www.cabdirect.org/cabdirect/abstract/20133258384

Wander, A. E. (2006). A competitividade do agronegócio brasileiro de arroz. Custos e Agronegócio Online, 2(1), 1-14.

Yeats, A. J. (1998). Does Mercosur's trade performance raise concerns about the effects of regional trade arrangements? World Bank Economic Review, 12(1), 1-28. https://doi.org/10.1093/wber/12.1.1

Zanin, V., \& Bacchi, M. R. P. (2017). Determinantes das exportações brasileiras de arroz. Revista de Economia e Agronegócio, 15(3), 545-572. https://doi.org/10.25070/rea.v15i3.468 